\title{
Effects of Nitrite on Development of Embryos and Early Larval Stages of the Zebrafish (Danio rerio)
}

\author{
Alison E. Simmons, Ida Karimi, ${ }^{1}$ Mayank Talwar, ${ }^{2, *}$ and Thomas W. Simmons ${ }^{2}$
}

\begin{abstract}
Epidemiological studies suggest that high nitrate levels in food and water may cause birth defects or spontaneous abortions in humans. Experimental mammalian studies show that high nitrite levels adversely affect reproductive outcomes, but have not shown congenital malformations. Consequently, the teratogenic potential of nitrite is unclear. In this study, the effects of nitrite on development of zebrafish embryos and early larval stages were investigated. Eggs were exposed to ethanol (a known teratogen), nitrite, or nitrate for 24 or 96 hours, and larvae examined at 120 hours. Sublethal exposure to $300 \mathrm{mM}$ ethanol for 24 hours caused severe pericardial and yolk sac edema, craniofacial and axial malformations, and swim bladder noninflation. The 96 hour $\mathrm{LC}_{50}$ for nitrite was $411 \mathrm{mg} / \mathrm{L}$. Less severe edema, craniofacial (but not axial) malformations, swim bladder noninflation, and immobility were observed after sublethal exposure to nitrite between 10 and $300 \mathrm{mg} / \mathrm{L}$ for 96 hours. Exposure to nitrite for 24 hours at concentrations as high as $2000 \mathrm{mg} / \mathrm{L}$ was not lethal. Only axial malformations and swim bladder noninflation were observed at $1500 \mathrm{mg} / \mathrm{L}$. The results demonstrate that sublethal nitrite concentrations cause developmental defects. The type and magnitude of these defects differed after 24 and 96 hours of exposure.
\end{abstract}

\section{Introduction}

$\mathbf{N}$ ITRATE IS A NATURALLY OCCURRING inorganic ion found in soil and water that plays an important role in the nitrogen cycle as a primary plant nutrient. However, excess nitrogen in the environment from sources such as inorganic and organic fertilizers can cause high levels of nitrate in drinking water and food. ${ }^{1}$ Nitrate ingested by humans is converted to nitrite by intestinal and salivary bacteria. Absorption and circulation of nitrite in infants is known to cause methemoglobinemia or 'blue baby syndrome,' a condition in which greater than $2 \%$ of the hemoglobin is oxidized to methemoglobin, resulting in oxygen deprivation. ${ }^{2}$ In addition, there are some concerns that exposure to elevated levels of nitrate may be linked to carcinogenesis and teratogenesis. ${ }^{3}$ Consequently, many international organizations and nations have developed guidelines and regulations for nitrate in drinking water and food, and have established acceptable daily intakes and references doses. ${ }^{4}$

The role of nitrite as a reproductive and developmental toxicant is unclear. Some epidemiological studies suggest that nitrite is a teratogen causing birth defects or spontaneous abortions in humans. However, a cause and effect relation- ship has not been established..$^{5-7}$ Although experimental mammalian studies have shown that high levels of nitrite adversely affect reproductive outcomes (e.g., fetal loss, reduced number of litters and live births, and neonatal mortality), they have not produced congenital malformations. ${ }^{5-7}$ Nevertheless, further research on the teratogenic potential of nitrite has been recommended because some epidemiological studies have shown an increased risk of central nervous system or neural tube defects in populations exposed to high nitrate in drinking water and food. ${ }^{7}$

The zebrafish has become a widely used experimental model for developmental toxicology. ${ }^{8,9}$ For example, the developmental toxicity of dioxin has been extensively studied in the zebrafish to understand the cellular and molecular mechanisms underlying organ level defects caused by this well-known teratogen. ${ }^{10}$ Similar efforts are underway to elucidate the basis of fetal alcohol syndrome. ${ }^{11}$ In addition, assays are being developed to screen environmental chemicals and drugs for possible embryotoxic and teratogenic effects. ${ }^{12,13}$ For example, the teratogenic potential of 31 compounds was tested using a dechorionated embryo teratogenicity assay, and $87 \%$ of the compounds were successfully categorized as either teratogens or nonteratogens. ${ }^{14}$

\footnotetext{
${ }^{1}$ Indiana Area Senior High School, Indiana, Pennsylvania.

${ }^{2}$ Department of Biology, Indiana University of Pennsylvania, Indiana, Pennsylvania.

*Present address: Department of Biochemistry and Molecular Biology, College of Medicine, University of Florida, Gainesville, Florida.
} 
A review of the literature shows that the teratogenic potential of nitrite has not been explored using the zebrafish model. The viability of zebrafish embryos exposed to wastewater and its components such as nitrite has been reported in a study comparing the zebrafish embryo test to a traditional acute toxicity test using juvenile rainbow trout. ${ }^{15}$ The effects of acute exposure to nitrite on survival of larvae, and subchronic exposure on growth of juveniles have also been studied in zebrafish. ${ }^{16,17}$

In our study, the potential direct effects of nitrite on development were tested in the zebrafish, and ethanol was used as a positive control.

\section{Materials and Methods}

Adult zebrafish distributed by International Pet Resources (Hillsdale, NJ) were purchased from Pearce's Pet Place (Indiana, PA). A breeding colony was established in an environmental growth chamber (Environmental Growth Chambers, Chagrin Falls, $\mathrm{OH}$ ) kept at $28.0 \pm 0.5^{\circ} \mathrm{C}$ with a $14 \mathrm{~h}$ light $/ 10 \mathrm{~h}$ dark photoperiod. A simple method for steady, low-level embryo production was adapted from The Zebrafish Book. ${ }^{18}$ Six 10-gallon tanks, each containing 4 male and 8 female zebrafish, were used. Fish were fed twice daily with either TetraMin ${ }^{\circledR}$ Tropical Flakes (Tetra, Blacksburg, VA) or Bio-Pure ${ }^{\circledR}$ Frozen Brine Shrimp (Hikari Sales U.S.A., Inc., Hayward, CA). The night before breeding days, a single layer of marbles was placed on the tank bottoms to protect eggs from predation. The following morning $1 \mathrm{~h}$ after onset of the light cycle, fertilized eggs were collected by siphoning into a fine-meshed nylon net that was then inverted in a finger bowl containing tank water.

A static renewal method adapted from similar experiments with ethanol and dioxin was used. ${ }^{19-21}$ Within $2 \mathrm{~h}$ of collection, eggs were separated from debris and transferred with a pipette to glass Petri dishes containing $100 \mathrm{~mL}$ of $60 \mathrm{mg} / \mathrm{L}$ Instant Ocean ${ }^{\circledR}$ (Spectrum Brands, Inc.) salts and test compounds in distilled water. Zebrafish (3 replicates per concentration and 25 eggs per replicate) were exposed for 24 or $96 \mathrm{~h}$ post fertilization (hpf) to ethanol, sodium nitrite, or sodium nitrate, and examined at $120 \mathrm{hpf}$. Zebrafish eggs, embryos, and larvae were transferred daily to Petri dishes containing freshly-made test solutions. Sodium nitrate and sodium nitrite solutions were made daily to minimize oxidation of nitrite to nitrate. Nitrate and nitrite concentrations were measured using the Hach Co. (Loveland, CO) NitraVer ${ }^{\circledR} 5$

Table 1. Developmental Defects in Zebrafish Larvae AT 120 hPF After Exposure to Ethanol fOr $24 \mathrm{HPF}$

\begin{tabular}{lcc}
\hline & \multicolumn{2}{c}{ Treatment } \\
\cline { 2 - 3 } & $\begin{array}{c}\text { 0mM } \\
\text { ethanol }\end{array}$ & $\begin{array}{c}300 \mathrm{mM} \\
\text { ethanol }\end{array}$ \\
\hline Survival (\%) & $83.2 \pm 4.5$ & $82.6 \pm 9.3$ \\
Swim bladder noninflation (\%) & 0 & $46.6 \pm 13.6^{*}$ \\
Pericardial/yolk sac edema (\%) & 0 & $42.9 \pm 11.8^{*}$ \\
Craniofacial malformations (\%) & 0 & $50.5 \pm 16.5^{*}$ \\
Axial malformations (\%) & 0 & $18.7 \pm 12$ \\
\hline
\end{tabular}

Results are reported as Mean \pm SEM for 3 replicates and 25 eggs per replicate. Significant differences from control are shown by asterisks.
Cadmium Reduction Method 8039 and NitriVer ${ }^{\circledR} 3$ Diazotization Method 8507, respectively. A blind study approach was used to avoid observational bias. Observers scored larvae for pericardial edema, yolk sac edema, craniofacial and axial malformations, swim bladder noninflation, immobility, and death without knowing their treatment groups. Larvae were defined as dead if there were no signs of heart beat, blood circulation, or mobility after $1 \mathrm{~min}$ of observation. In some cases, larvae were selected for measurement of eye diameter and inter-eye distance using an Olympus $\mathrm{BH}-2$ microscope equipped with a calibrated ocular micrometer. Representative developmental defects were photo-documented using a Nikon SMZ-10 stereomicroscope equipped with a SPOT Idea digital microscope camera (SPOT Imaging Solutions ${ }^{\mathrm{TM}}$, Sterling Heights, MI).

In the first experiment, zebrafish were exposed to 0 and $300 \mathrm{mM}$ ethanol for $24 \mathrm{hpf}$ while the Petri dishes were covered with Parafilm ${ }^{\circledR}$ to reduce volatilization and loss of ethanol. In the second experiment, zebrafish were exposed to 0 to $1000 \mathrm{mg} / \mathrm{L}$ nitrite at intervals of $100 \mathrm{mg} / \mathrm{L}$ and $1000 \mathrm{mg} / \mathrm{L}$ nitrate for $96 \mathrm{hpf}$ to determine lethal concentrations. In the third experiment, zebrafish were exposed to $0,1,10,100,200$, and $300 \mathrm{mg} / \mathrm{L}$ nitrite and $300 \mathrm{mg} / \mathrm{L}$ nitrate for $96 \mathrm{hpf}$ to assess sublethal developmental effects. In the fourth experiment, zebrafish were exposed to 0 to $2000 \mathrm{mg} / \mathrm{L}$ nitrite at intervals of $250 \mathrm{mg} / \mathrm{L}$ and $2000 \mathrm{mg} / \mathrm{L}$ nitrate for $24 \mathrm{hpf}$ to determine lethal concentrations. In the fifth experiment, zebrafish were exposed to $0,250,500,750,1000$, and $1500 \mathrm{mg} / \mathrm{L}$ nitrite and $1500 \mathrm{mg} / \mathrm{L}$ nitrate for $24 \mathrm{hpf}$ to assess sublethal developmental effects.
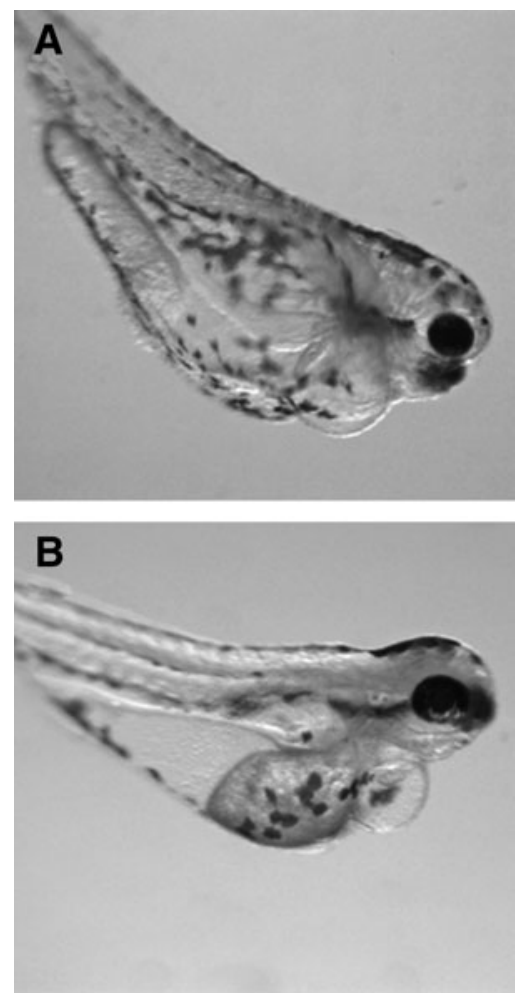

FIG. 1. Antero-lateral view of zebrafish larva at $120 \mathrm{hpf}$ after exposure to $300 \mathrm{mM}$ ethanol for $24 \mathrm{hpf}$ (A) or $300 \mathrm{mg} / \mathrm{L}$ nitrite for $96 \mathrm{hpf}$ (B). 
Table 2. Eye Diameter and Inter-eye Distance in Zebrafish Larvae With and Without Pericardial and Yolk Sac Edema at 120 HPF After Exposure TO ETHANOL FOR $24 \mathrm{HPF}$

\begin{tabular}{|c|c|c|c|}
\hline & \multicolumn{3}{|c|}{ Treatment and condition } \\
\hline & $\begin{array}{c}0 \mathrm{mM} \\
\text { ethanol }\end{array}$ & $\begin{array}{c}300 \mathrm{mM} \\
\text { ethanol } \\
\text { without edema }\end{array}$ & $\begin{array}{c}300 \mathrm{mM} \\
\text { ethanol } \\
\text { with edema }\end{array}$ \\
\hline Eye diameter $(\mu \mathrm{m})$ & $326.7 \pm 4.3$ & $305.9 \pm 5.1$ & $184.7 \pm 4.6^{*}$ \\
\hline $\begin{array}{l}\text { Inter-eye distance } \\
\quad(\mu \mathrm{m})\end{array}$ & $96.2 \pm 2.6$ & $105.7 \pm 6.3$ & $210.3 \pm 11.7^{*}$ \\
\hline
\end{tabular}

Results are reported as Mean \pm SEM for 15 individuals from 5 individuals per replicate. Significant differences from control are shown by asterisks.

Percent response data were arcsine square-root transformed and analyzed using one-way ANOVA and Student's $t$-test. Differences were considered statistically different at $p<0.05$. The median lethal concentration was calculated by linear regression of $\log _{10}$ transformed chemical concentration and probit transformed percent response data. ${ }^{22}$

Zebrafish embryos and larvae were euthanized by submersion in ice water for at least $10 \mathrm{~min}^{23}$ This study was approved by the Indiana University of Pennsylvania Institutional Animal Care and Use Committee.

\section{Results}

In the first experiment,a significant number of zebrafish larvae exposed to $300 \mathrm{mM}$ ethanol for $24 \mathrm{hpf}$ showed severe pericardial and yolk sac edema, craniofacial defects including a shortened snout and malformed mouth, and swim bladder noninflation at $120 \mathrm{hpf}$ (Table 1 and Fig. 1A). Craniofacial defects also included abnormal eye development. The eye diameter was considerably smaller and the inter-eye distance larger in larvae with edema from the treatment group compared to larvae without edema from the treatment and control groups (Table 2). Ten larvae exposed to ethanol also exhibited tail crooks and curves, although the effect was not statistically significant due to large variation between replicates (Table 1).
No difference in mortality was observed in the control and treatment groups.

In the second experiment, exposure of zebrafish to nitrite for $96 \mathrm{hpf}$ caused mortality starting at a concentration of $400 \mathrm{mg} / \mathrm{L}$ with a rapid increase in mortality at higher concentrations and no survival at $1000 \mathrm{mg} / \mathrm{L}$ (Fig. 2). The $\mathrm{LC}_{50}$ for nitrite was calculated to be $411 \mathrm{mg} / \mathrm{L}$. In contrast, nitrate at $1000 \mathrm{mg} / \mathrm{L}$ caused no mortality (Fig. 2).

In the third experiment, sublethal exposure of zebrafish to nitrite for $96 \mathrm{hpf}$ caused swim bladder noninflation at $100 \mathrm{mg} / \mathrm{L}$ and higher, and pericardial and yolk sac edema and craniofacial defects at 200 and $300 \mathrm{mg} / \mathrm{L}$ (Table 3). The pericardial and yolk sac edema were not as severe as in the ethanol exposure experiment (Fig. 1B), nor was the decrease in eye diameter and increase in inter-eye distance (Table 4). In addition, all larvae were immobile and 5 had crooked or curved tails at 200 and $300 \mathrm{mg} / \mathrm{L}$ (Table 3), although the axial malformations were again not statistically significant due to large variation between replicates. Exposure to $300 \mathrm{mg} / \mathrm{L} \mathrm{ni-}$ trate had no observable effect on development.

In the fourth experiment, exposure of zebrafish to nitrite and nitrate concentrations as high as $2000 \mathrm{mg} / \mathrm{L}$ for $24 \mathrm{hpf}$ had no effect on survival. In the fifth experiment, exposure of zebrafish to $1500 \mathrm{mg} / \mathrm{L}$ nitrite did not cause pericardial and yolk sac edema, craniofacial malformations, or immobility, but did cause swim bladder noninflation and a significant number of axial malformations (Table 5 and Fig. 3).

\section{Discussion}

As a positive control for our study, we replicated the experiments of other researchers who investigated the effects of ethanol on zebrafish development. ${ }^{19,21}$ Their studies showed that zebrafish exposed to $1.5 \%(328 \mathrm{mM})$ ethanol from 6 to $24 \mathrm{hpf}$ had insignificant mortality $(\sim 15 \%)$, while $60 \%$ displayed enlarged body size, small eye diameter $(\sim 50 \%$ reduction) and large inter-eye distance, and craniofacial defects at 72 hpf. ${ }^{19}$ Likewise, zebrafish exposed to $300 \mathrm{mM}$ ethanol from 3 to $24 \mathrm{hpf}$ had insignificant mortality ( $\sim 10 \%)$, while over $75 \%$ displayed yolk sac and pericardial edema, and axial malformations at $120 \mathrm{hpf}^{21}$ Small eye diameter and large inter-eye distance, and craniofacial defects were also noted
FIG. 2. Survival of zebrafish larvae at $120 \mathrm{hpf}$ after exposure to nitrite and nitrate (where indicated) for $96 \mathrm{hpf}$. Results are reported as Mean \pm SEM for 3 replicates and 25 eggs per replicate. Significant differences from control are shown by asterisks.

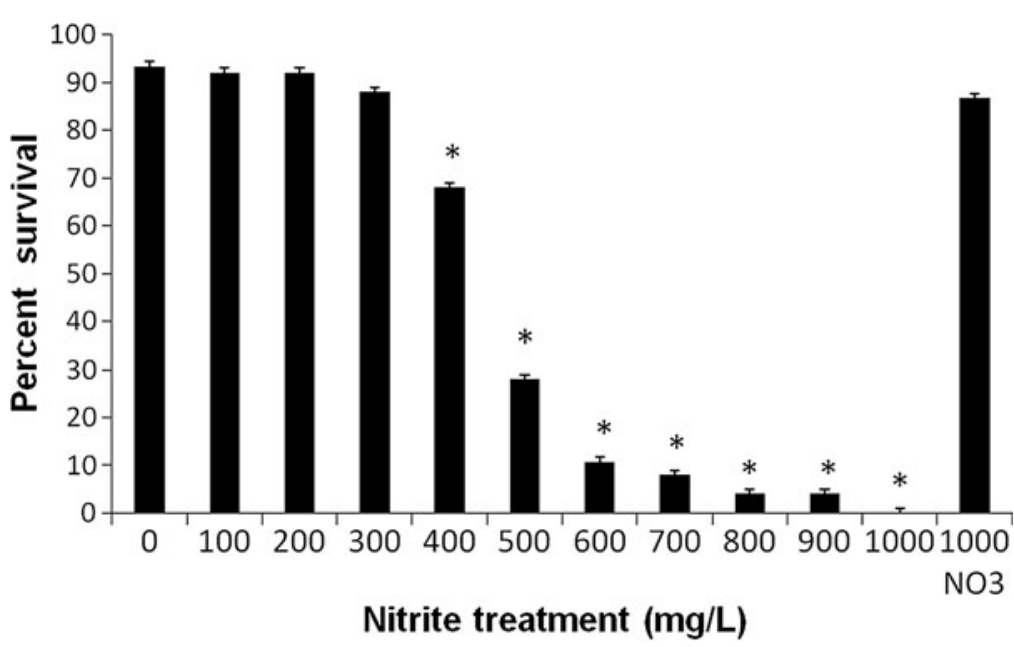


Table 3. Developmental Defects in Zebrafish Larvae at 120 hpf After Exposure TO NitRITE OR NitRATE FOR 96 HPF

\begin{tabular}{lccccc}
\hline & \multicolumn{4}{c}{ Treatment } \\
\cline { 2 - 6 } & $0 m g / L$ nitrite & $100 m g / L$ nitrite & $200 m g / L$ nitrite & $300 m g / L$ nitrite & $300 \mathrm{mg} / \mathrm{L}$ nitrate \\
\hline Swim bladder noninflation (\%) & 0 & $100^{*}$ & $100^{*}$ & $100^{*}$ & 0 \\
Pericardial/yolk sac edema (\%) & 0 & $42.2 \pm 21.2$ & $94.8 \pm 26.9^{*}$ & $97.8 \pm 2.2^{*}$ & 0 \\
Craniofacial malformations (\%) & 0 & $66.7 \pm 33.3$ & $88.4 \pm 6.4^{*}$ & $100^{*}$ & 0 \\
Axial malformations (\%) & 0 & 0 & $4.2 \pm 2.2$ & $7.5 \pm 3.9$ & 0 \\
Immobility (\%) & 0 & $51.9 \pm 28.9$ & $92.1 \pm 4.0^{*}$ & $100^{*}$ & 0 \\
\hline
\end{tabular}

Results are reported as Mean \pm SEM for 3 replicates and 25 eggs per replicate. Significant differences from control are shown by asterisks. No defects were observed at 1 and $10 \mathrm{mg} / \mathrm{L}$ nitrite.

but not quantified. Although not noted in these studies, the photographs of zebrafish exposed to ethanol clearly show that the swim bladder was not inflated. In our study, $40 \%-50 \%$ of zebrafish exposed to $300 \mathrm{mM}$ ethanol displayed pericardial and yolk sac edema, small eye diameter ( $\sim 50 \%$ reduction) and large inter-eye distance, and craniofacial defects. In addition, the swim bladder did not inflate in the affected zebrafish and $19 \%$ had axial defects. The similarity between our results and the findings of these other studies validated our rearing methods and experimental conditions.

In the following discussion, the effects of nitrite are compared to 2,3,7,8-tetrachlorobenzo- $p$-dioxin (TCDD) and ethanol which have relatively high and low developmental toxicity to zebrafish, respectively. ${ }^{13}$ In our study, the $96 \mathrm{~h} \mathrm{LC}_{50}$ for zebrafish continuously exposed to nitrite was $411 \mathrm{mg} / \mathrm{L}$ ( $8.9 \mathrm{mM})$. Similarly, in other studies, the $96 \mathrm{~h} \mathrm{LC}_{50}$ for zebrafish embryos exposed to sodium nitrite was $436 \mathrm{mg} / \mathrm{L}$ (291 mg/L nitrite) ${ }_{,}^{15}$ and the $96 \mathrm{~h} \mathrm{LC}_{50}$ for juvenile zebrafish exposed to nitrite was 386 and $242 \mathrm{mg} / \mathrm{L}$ for $20-25$ days and 2-3 months of age, respectively. ${ }^{16}$ A sublethal concentration of $73 \mathrm{mg} / \mathrm{L}$ nitrite was shown to suppress the growth rate of zebrafish between 20 and 48 days of age with no mortality. ${ }^{17}$ In contrast to $96 \mathrm{~h}$ exposure regimes, in our study no significant mortality was observed in zebrafish exposed for $24 \mathrm{hpf}$ to nitrite concentrations as high as $2000 \mathrm{mg} / \mathrm{L}$ $(43.5 \mathrm{mM})$. These $\mathrm{LC}_{50}$ values are relatively high compared to a number of other compounds known to cause developmental toxicity in zebrafish embryos exposed for similar time periods. For example, the $96 \mathrm{~h} \mathrm{LC}_{50}$ values range from $0.026 \mu \mathrm{M}$ for TCDD to $1.26 \mathrm{mM}$ for atrazine; and the $24 \mathrm{~h} \mathrm{LC}_{50}$ values range from $1.87 \mu \mathrm{M}$ for methylisothiocyanate to $340 \mathrm{mM}$ for ethanol. $^{13,21,24}$

Predictably, nitrate did not cause significant mortality in our study. Nitrate is known to be much less toxic than nitrite

Table 4. Eye Diameter and Inter-eye Distance in Zebrafish Larvae at 120 hpF After Exposure TO NITRITE FOR 96 HPF

\begin{tabular}{lcc}
\hline & \multicolumn{2}{c}{ Treatment } \\
\cline { 2 - 3 } & $0 m g / L$ nitrite & $300 m g / L$ nitrite \\
\hline Eye diameter $(\mu \mathrm{m})$ & $335.6 \pm 2.4$ & $233.4 \pm 4.3^{*}$ \\
Inter-eye distance $(\mu \mathrm{m})$ & $108.7 \pm 1.6$ & $163.4 \pm 11.2^{*}$ \\
\hline
\end{tabular}

Results are reported as Mean \pm SEM for 15 individuals from 5 individuals per replicate. Significant differences from control are shown by asterisks. to aquatic vertebrates at all stages of development for those species that have been tested. For example, the $96 \mathrm{~h} \mathrm{LC}_{50}$ for fish eggs, larvae, fry, and fingerlings reportedly ranges from $846 \mathrm{mg} / \mathrm{L}$ (Poecilia reticulates) to over $13,290 \mathrm{mg} / \mathrm{L}$ (Pomacentus leucostritus) for nitrate, ${ }^{25}$ while the $96 \mathrm{~h} \mathrm{LC}_{50}$ for juvenile and adult fish ranges from $0.79 \mathrm{mg} / \mathrm{L}$ (Salmo gairdneri) to $461 \mathrm{mg} / \mathrm{L}$ (Micropterus salmoides) for nitrite. ${ }^{26}$

In our study, the lowest observed effect concentration (LOEC) for nitrite that caused yolk sac and pericardial edema, craniofacial malformations including a reduction in eye size, swim bladder noninflation and immobility in zebrafish exposed for $96 \mathrm{hpf}$ was $100 \mathrm{mg} / \mathrm{L}(2.17 \mathrm{mM})$. The LOEC that caused axial defects was $200 \mathrm{mg} / \mathrm{L}(4.35 \mathrm{mM})$. The LOEC for $24 \mathrm{hpf}$ exposure that caused swim bladder noninflation and axial malformations was $1500 \mathrm{mg} / \mathrm{L}(32.6 \mathrm{mM})$. These morphological and functional defects are a common set of outcomes for developmental toxicity in zebrafish. Similar to $\mathrm{LC}_{50}$ values for nitrite, these are relatively high LOEC values compared to other compounds that adversely affect zebrafish development. ${ }^{13}$ For example, the lowest effective dose that causes gross morphological defects after exposure for $96 \mathrm{hpf}$ to TCDD and ethanol is $0.005 \mu \mathrm{M}$ and $1 \%(218 \mathrm{mM})$, respectively; and after exposure for $48 \mathrm{hpf}$ to TCCD and $24 \mathrm{hpf}$ to ethanol is $0.1 \mu \mathrm{M}$ and $200 \mathrm{mM}$, respectively. ${ }^{21,24,27}$

Overall, nitrite caused developmental defects in zebrafish at concentrations close to those for ethanol, a known human

\section{Table 5. Developmental Defects in Zebrafish Larvae at 120 hPF After Exposure to Nitrite OR NITRATE FOR 24 HPF}

\begin{tabular}{lccc}
\hline & \multicolumn{3}{c}{ Treatment } \\
\cline { 2 - 4 } & $\begin{array}{c}0 \mathrm{mg} / \mathrm{L} \\
\text { nitrite }\end{array}$ & $\begin{array}{c}1500 \mathrm{mg} / \mathrm{L} \\
\text { nitrite }\end{array}$ & $\begin{array}{c}1500 \mathrm{mg} / \mathrm{L} \\
\text { nitrate }\end{array}$ \\
\hline $\begin{array}{c}\text { Swim bladder } \\
\text { noninflation (\%) }\end{array}$ & 0 & $50.0 \pm 25.3^{*}$ & 0 \\
$\begin{array}{l}\text { Pericardial/yolk sac } \\
\quad \text { edema (\%) }\end{array}$ & $2.8 \pm 2.8$ & $3.0 \pm 1.5$ & 0 \\
$\begin{array}{c}\text { Craniofacial } \\
\text { malformations (\%) }\end{array}$ & $2.8 \pm 2.8$ & 0 & 0 \\
$\begin{array}{c}\text { Axial malformations (\%) } \\
\text { Immobility (\%) }\end{array}$ & 0 & $36.7 \pm 23.5^{*}$ & 0 \\
\hline
\end{tabular}

Results are reported as Mean \pm SEM for 3 replicates and 25 eggs per replicate. Significant differences from control are shown by asterisks.

No defects were observed at 250, 500, 750, and $1000 \mathrm{mg} / \mathrm{L}$ nitrite. 

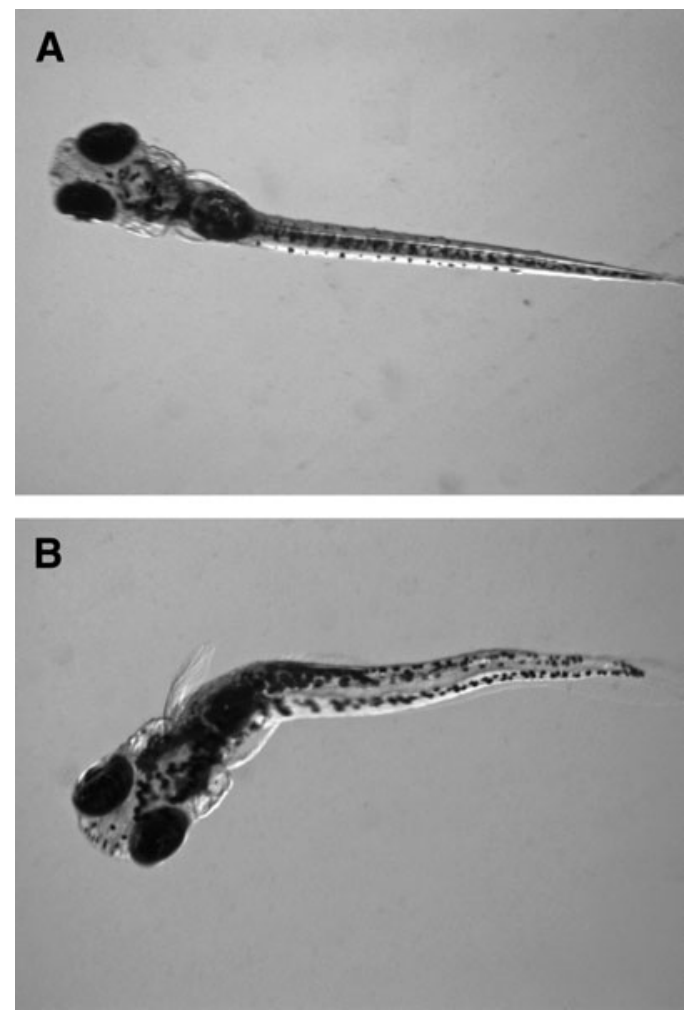

FIG. 3. Dorsal view of zebrafish larva at $120 \mathrm{hpf}$ after exposure to $0 \mathrm{mg} / \mathrm{L}$ (A) or $1500 \mathrm{mg} / \mathrm{L}$ (B) nitrite for $24 \mathrm{hpf}$.

teratogen. However, the extent of the defects was different. Zebrafish exposed to nitrite for $24 \mathrm{hpf}$ only showed axial abnormalities, whereas zebrafish exposed to ethanol showed a host of malformations. In addition, the pericardial and yolk sac edema, and reduction in eye size seen in zebrafish exposed to nitrite for $96 \mathrm{hpf}$ was less severe than in zebrafish exposed to ethanol for $24 \mathrm{hpf}$. It should be noted that the effects of nitrite are probably independent of hemoglobin oxidation to methemoglobin. Oxygen-dependent physiological processes in zebrafish at least to age $96 \mathrm{hpf}$ are not affected by functional ablation of hemoglobin using carbon monoxide and pheylhydrazine. $^{28}$

Because we do not know the actual dose of nitrite in the exposed zebrafish, and there is very limited information on the blood levels of nitrite in humans due to high environmental exposure, it is difficult to determine if the nitrite concentrations used in our study are environmentally relevant. However, it is known that absorption of ingested nitrate is rapid and complete, and $7 \%$ of the absorbed nitrate is secreted and converted to nitrite in saliva. ${ }^{29}$ For example, administration of $217 \mathrm{mg}$ radiolabeled nitrate in $10 \mathrm{~mL}$, followed by $200 \mathrm{~mL}$ drinking water, to twelve volunteers showed peak concentrations of nitrate in plasma $(10.5 \mathrm{mg} / \mathrm{L})$ and saliva $(155 \mathrm{mg} / \mathrm{L})$, and nitrite in saliva $(24.4 \mathrm{mg} / \mathrm{L})$ within 1 hour after dosing. ${ }^{30}$ Likewise, about $90 \%$ of nitrate administered in vegetable diets (564 to $1013 \mathrm{mg}$ ) to twelve volunteers was bioavailable, although peak plasma levels (17.8 to $57.5 \mathrm{mg} /$ $\mathrm{kg}$ ) were not observed until 0.67 to $3.0 \mathrm{~h}$ after ingestion. ${ }^{30}$ Plasma levels of nitrite in most samples were below detection $(<0.2 \mathrm{mg} / \mathrm{kg})$, and detectable levels were between only 0.2 and $0.25 \mathrm{mg} / \mathrm{kg}$. It is also known that nitrite crosses the pla- centa and causes methemoglobin formation in fetuses. For example, dams injected with $30 \mathrm{mg} / \mathrm{L}$ of sodium nitrite showed a peak nitrite concentration of $9.4 \mathrm{mg} / \mathrm{L}$ in fetal blood between 30 and $45 \mathrm{~min}$ after dosing. ${ }^{31}$ Therefore, the kinetics of nitrite in humans and experimental animals suggest that fetuses may be at risk of exposure if mothers ingest water and food containing high levels of nitrate.

In conclusion, nitrite should be added to the list of compounds known to have developmental toxicity in zebrafish. ${ }^{13}$ In addition, our findings when considered in light of other studies that associate an increase in birth defects with elevated nitrate concentrations in drinking water, ${ }^{13}$ support the need for further investigation on the developmental toxicity of nitrite using the zebrafish model system.

\section{Acknowledgments}

This research was funded by a Mary Anne Stock Student Research Award from the Allegheny-Erie Chapter of the Society of Toxicology to I. Karimi and A.E. Simmons; and an Undergraduate Student Research Award from the Indiana University of Pennsylvania School of Graduate Studies and Research to M. Talwar.

\section{Author Contributions}

Ms. Alison Simmons and Ms. Ida Karimi are seniors at the Indiana Area Senior High School and will be graduating in June 2012. As juniors in high school, they were laboratory partners in an Advanced Placement biology course taught by Mr. William Waryck. Under the guidance of Dr. Thomas Simmons, in the spring of 2011 they joined the Allegheny-Erie Chapter of the Society of Toxicology (A-E SOT), and applied for and received a student research grant from the society. In the summer of 2011, they conducted this study under the close supervision of Dr. Simmons while taking a college physics course at Indiana University of Pennsylvania (IUP). Ms. Simmons and Ms. Karimi were involved in all aspects of this study from establishing and maintaining the zebrafish colony, planning and running the experiments, analyzing and evaluating the results, to writing and submitting the manuscript. Ms. Simmons and Ms. Karimi will be presenting a poster of their work in April 2012 at the IUP Women in Mathematics, Science and Technology Program, and at the A-E SOT spring conference.

Mr. Mayank Talwar holds a Bachelor of Arts in Biology degree from IUP with minors in Mathematics and Chemistry, a Master of Science in Biotechnology degree from Pennsylvania State University, and he is currently pursuing a Doctor of Philosophy in Biochemistry and Molecular Biology degree at the University of Florida. In 2011 he received a Pre-doctoral T32 Training Grant in Cancer Biology Fellowship to support his doctoral studies. During the summer between completing his master's degree and beginning his doctoral studies, Mr. Talwar was a research assistant in experimental therapeutics at the Walter Reed Army Institute of Research. While at IUP, Mr. Talwar was enrolled in the Biology Honors Research Program from 2006 to 2008 and Dr. Simmons was his thesis advisor. Mr. Talwar conducted a pilot study on exposure of zebrafish to nitrite and the present work is based on his preliminary findings. Mr. Talwar received an Undergraduate Student Research Grant from the IUP School of Graduate Studies and Research to support his research, and he 
presented a poster of his work at the IUP Undergraduate Scholars Forum in April 2008. Mr. Talwar reviewed and edited this manuscript.

Dr. Thomas Simmons holds a Bachelor of Arts in Zoology degree from the State University of New York at Oswego, a Master of Arts in Biology degree from the State University of New York at Oneonta, and a Doctor of Philosophy in Biological Sciences degree from St. John's University, New York. He was a postdoctoral fellow in the toxicology training program at the University of Rochester School of Medicine. Dr. Simmons is a Professor of Biology at IUP and has been teaching and conducting research at the university for 21 years. He is a member of the Society of Toxicology, the Allegheny-Erie Chapter of the Society of Toxicology, and the Society of Environmental Toxicology and Chemistry. Dr. Simmons is the principal investigator and worked closely with his students on all aspects of this study.

\section{Disclosure Statement}

No competing financial interests exist.

\section{References}

1. Addiscott TM, Whitmore AP, Powlson DS. Farming, Fertilizers and the Nitrate Problem. CAB International, Wallingford, UK, 1991.

2. Kross BC, Ayebo AD, Fuortes LJ. Methemoglobinemia: Nitrate toxicity in rural America. Am Fam Physician 1992;46: 183-188.

3. McKnight GM, Duncan CW, Leifert C, Golden MH. Dietary nitrate in man: Friend or foe? Br J Nutr 1999;81:349-358.

4. L'hirondel H, L'hirondel J-L. Nitrate and Man: Toxic, Harmless or Beneficial? CABI Publishing, Wallingford, Oxon, UK, 2002.

5. Fan AM, Willhite CC, Book SA. Evaluation of the nitrate drinking water standard with reference to infant methemoglobinemia and potential reproductive toxicity. Regul Toxicol Pharmacol 1987;7:135-148.

6. Fan AM, Steinberg, VE. Health implications of nitrate and nitrite in drinking water: An update on methemoglobinemia occurrence and reproductive and developmental toxicity. Regul Toxicol Pharmacol 1996;23:35-43.

7. Manassaram DM, Backer, LC, Moll DM. A review of nitrates in drinking water: Maternal exposure and adverse reproductive and developmental outcomes. Environ Health Perspectives 2006;114:320-327.

8. Teraoka H, Dong W, Hiraga T. Zebrafish as a novel experimental model for developmental toxicology. Congen Anom 2003;43:123-132.

9. Yang L, Alshut R, Legradi J, Weiss C, Reischl M, Mikut R, Liebel U, Muller F, Strahle U. Zebrafish embryos as models for embryotoxic and teratological effects of chemicals. Reprod Toxicol 2009;28:245-253.

10. Carney SA, Prasch AL, Heidemann W, Peterson RE. Understanding dioxin developmental toxicity using the zebrafish model. Birth Defects Res A Clin Mol Teratol 2006; 76:7-18.

11. Tanguay RL, Reimers MJ. Analysis of Ethanol Developmental Toxicity in Zebrafish. In: Alcohol: Methods and Protocols (Methods in Molecular Biology). Nagy LE (ed.), pp. 63-132. Springer-Verlag, New York, NY, 2008.

12. Augustine-Rauch $\mathrm{K}$, Zhang CX, Panzica-Kelly JM. In vitro developmental toxicology assays: A review of the state of the science of rodent and zebrafish whole embryo culture and embryonic stem cell assays. Birth Defects Res C Embryo Today Rev 2010;90:87-98.

13. McCollum CW, Ducharme NA, Bondesson M, Gustafsson J-A. Developmental toxicity screening in zebrafish. Birth Defects Res C Embryo Today Rev 2011;93:67-114.

14. Brannen KC, Panzaica-Kelly JM, Danberry TL, AugustineRauch KA. Development of a zebrafish embryo teratogenicity assay and quantitative prediction model. Birth Defects Res B Dev Repro Toxicol 2010;89:66-77.

15. Lahnsteiner, F. The sensitivity and reproducibility of the zebrafish (Danio rerio) embryo test for the screening of waste water quality and for testing the toxicity of chemicals. ATLA 2008;36:299-311.

16. Voslarova, E, Pistekova, V, Svobodova, Z. Nitrite toxicity to Danio rerio: Effects of fish age and chloride concentations. Acta Vet Brno 2006;75:107-113.

17. Voslarova E, Pistekova V, Svobodova Z, Bedanova I. Nitrite toxicity to Danio rerio: Effects of subchronic exposure on fish growth. Act Vet Brno 2008;77:455-460.

18. Westerfield M: The Zebrafish Book: A Guide for the Laboratory Use of Zebrafish (Danio rerio), $5^{\text {th }} \mathrm{ed}$. University of Oregon Press, Eugene, OR, 2007.

19. Bilotta J, Barnett JA, Hancock L, Saszik S. Ethanol exposure alters zebrafish development: A novel model of fetal alcohol syndrome. Neurotoxicol Teratol 2004;26:737743.

20. Henry TR, Spitsbergen, JM, Hornung, MW, Abnet, CC, Peterson, RE. Early life stage toxicity of 2,3,7,8-tetrachlorodibenzo-pdioxin in zebrafish (Danio rerio). Toxicol Appl Pharmacol 1997; 142:56-68.

21. Reimers MJ, Flockton AR, Tanguay RL. Ethanol- and acetaldehyde-mediated development toxicity in zebrafish. Neurotoxicol Teratol 2004;26:769-781.

22. Finney DJ. Probit Analysis: A Statistical Treatment of the Sigmoid Response Curve. Cambridge University Press, Cambridge, England, 2009.

23. National Institutes of Health. Guidelines for Use of Zebrafish in the NIH Intramural Research Program. Animal Research and Care Guidelines, Office of Animal Care and Use, 2009. (http://oacu.od.nih.gov/ARAC/index.htm). Accessed on June 18, 2012.

24. Ton C, Lin Y, Willett C. Zebrafish as a model for developmental neurotoxicity testing. Birth Defects Research (Part A) 2006;76:553-567.

25. Camargo, JA, Alonso A, Salamanca A. Nitrate toxicity to aquatic animals: A review with new data for freshwater invertebrates. Chemosphere 2005;58:1255-1267.

26. Lewis WM, Morris DP. Toxicity of nitrite to fish: A review. Trans Am Fish Soc 1986;115:183-195.

27. Hallare A, Nagel K, Kohler, H-R, Triebskorn R. Comparative embryotoxicity and proteotoxicity of three carrier solvents to zebrafish (Danio rerio) embryos. Ecotoxicol Environ Safe 2006;63:378-388.

28. Pelster B, Burggren WW. Disruption of hemoglobin oxygen transport does not impact oxygen-dependent physiological processes in developing embryos of zebra fish (Danio rerio). Circ Res 1996;79:358-362.

29. Zeilmaker MJ, Bakker MI, Schothorst R, Slob W. Risk assessment of N-nitrosodimethylamine formed endogenously after fish-with-vegetable meals. Toxicol Sci 2010;116:323-335 (Supplementary Material A1: Mathematical model of human nitrate/nitrite kinetics, including the formation of methemoglobin in the blood). 
30. Lambers AC, Kortboyer JM, Schothorst RC, Sips AJAM, Cleven RFMJ, Meulenbelt CJ. The Oral Bioavailability of Nitrate From Vegetables Investigated in Healthy Volunteers. National Institute for Public Health and the Environment, Bilthoven, The Netherlands, RIVM Report 235802 014, 2000.

31. Gruener N, Shuval H, Behroozi K, Cohen S. Methemoglobinemia induced by transplacental passage of nitrites in rats. Bull Env Contam Toxicol 1973;9:44-48.
Address correspondence to: Thomas W. Simmons, Ph.D.

Department of Biology Indiana University of Pennsylvania 114 Weyandt Hall 975 Oakland Avenue Indiana, PA 15705

E-mail: tsimmons@iup.edu 